\title{
Penentuan Solusi Numerik Pada Model Mangsa-Pemangsa Dengan Pemanenan Pada Mangsa Menggunakan Metode Runge-Kutta-Fehlberg
}

\author{
Nurul Asyifa Solihatin ${ }^{1,}$ a) dan Elis Ratna Wulan ${ }^{1, b)}$ \\ ${ }^{1}$ UIN Sunan Gunung Djati Bandung \\ a)nurulasyifaso@gmail.com \\ b) elis ratnawulan@uinsgd.ac.id
}

\begin{abstract}
Abstrak
Model mangsa pemangsa dengan pemanenan pada mangsa merupakan pembaruan dari model mangsa pemangsa Lotka-Volterra, dimana pada model ini terdapat parameter pemanenan sebagai pengontrol populasi. Penyelesaian model mangsa pemangsa secara analitik dapat digunakan untuk memprediksi jumlah populasi pada saat yang diinginkan, namun tidak dapat memprediksi secara rinci jumlah populasi yang ada pada setiap pemantauan. Oleh karena itu metode numerik digunakan sebagai alternatif dalam penyelesaian masalah model mangsa pemangsa dengan pemanenan pada mangsa. Metode Runge-Kutta-Fehlberg digunakan penulis untuk menyelesaikan model mangsa pemangsa dengan pemanenan pada mangsa. Metode ini merupakan alternatif dari metode Taylor karena tidak memerlukan perhitungan turunan serta memiliki ketelitian yang tinggi. Hasil yang diperoleh pada studi kasus penelitian ini yaitu memiliki galat yang cukup kecil yaitu 0,0019404-0,027213 sehingga metode Runge-Kutta-Fehlberg merupakan metode yang teliti.

Kata Kunci: Sistem Persamaan Diferensial, Model Matematika, Model Mangsa Pemangsa, Fungsi Respon, Metode Runge-Kutta-Fehlberg.
\end{abstract}

\begin{abstract}
Predator prey model with harvesting of prey is an update of the Lotka-Volterra model. In this model there are harvest parameters as population control solving predator prey model analitically can be used to predict the population at certain time, but cannot predict in detail the number of exist populations. Therefore numerical method is proposed as alternative in solving the problem of predator prey model with harvesting of prey. This method is an alternative of the Taylor method because it does not require also has high accuracy. The result obtained that the Runge-Kutta-Fehlberg method was a meticulous method with very small error.
\end{abstract}

Keywords: Differensial Equation System, Mathematical Model, Response Function, Runge-Kutta-Fehlberg Method.

e-ISSN: 2686-0341 p-ISSN: 2338-0896 


\section{Pendahuluan}

Ekologi merupakan ilmu yang mempelajari interaksi antara makhluk hidup dengan lingkungannya [1]. Interaksi ini telah menjadi bahasan yang menarik dan telah dipelajari menggunakan model matematika oleh beberapa peneliti. Hampir semua permasalahan di dunia ini dapat diformulasikan ke dalam model matematika.

Salah satu model matematika yang membahas mengenai ekologi yaitu model rantai makanan. Model rantai makanan merupakan model populasi yang mempresentasikan perilaku dan juga perkembangan suatu spesies. Pada umumnya terdapat dua atau lebih spesies yang saling berinteraksi, sehingga keadaan suatu spesies dipengaruhi oleh keadaan spesies lain yang berinteraksi dengannya. Model matematika yang mempresentasikan rantai makanan yaitu model mangsa pemangsa.

Model mangsa pemangsa merupakan sistem persamaan diferensial non linier yang mempresentasikan interaksi antara mangsa dengan pemangsa disuatu lingkungan yang terbatas. Interaksi disini artinya yaitu kompetisi, dimana pemangsa akan memakan mangsa sesuai dengan kebutuhannya, jika tidak ada mangsa maka pemangsa tidak bisa hidup. Model mangsa pemangsa yang paling sederhana adalah model mangsa pemangsa Lotka-Volterra. Namun kenyataannya disuatu lingkungan hidup tidak selamanya mangsa akan mati jika dimangsa oleh pemangsa, tentu ada faktorfaktor lain yang menyebabkan jumlah populasi mangsa bertambah atau berkurang, begitupun dengan pemangsa.

Penyelesaian model mangsa pemangsa secara analitik dapat digunakan untuk memprediksi jumlah populasi pada saat yang diinginkan, namun tidak dapat memprediksi secara rinci jumlah populasi yang ada pada setiap pemantauan. Oleh karena itu metode numerik digunakan sebagai alternatif dalam penyelesaian masalah model mangsa pemangsa dengan pemanenan pada mangsa. Metode numerik juga digunakan sebagai alat bantu pemecahan masalah matematika dalam menyelesaikan sistem persamaan diferensial non linier yang tidak dapat diselesaikan secara analitik.

Terdapat beberapa metode numerik untuk menyelesaikan sistem persamaan diferensial LotkaVolterra, yaitu metode Taylor, metode Euler, Metode Bagi Dua, Metode Runge-Kutta, Metode RungeKutta-Fehlberg, Metode Dekomposisi Adomian Laplace, dan lain-lain. Dari metode yang ada, diharapkan dapat menghasilkan solusi numerik yang mendekati nilai sebenarnya dan memiliki ketelitian yang tinggi.

\section{Metode}

Sistem persamaan diferensial mangsa pemangsa merupakan sistem persamaan diferensial non linier. Dalam ekologi, sistem persamaan diferensial ini digunakan untuk memodelkan interaksi dua spesies yaitu spesies pemangsa dan spesies mangsa. Model mangsa pemangsa dengan faktor pemanenan pada mangsa merupakan perkembangan dari model mangsa pemangsa Lotka-Volterra dengan menambahkan variabel pemanenan. Model ini merupakan model mangsa pemangsa tipe Holling II dengan laju konsumsi pemangsa yang tidak dibatasi waktu. Hal ini terjadi kerena meskipun jumlah mangsa banyak sehingga pemangsa tidak perlu waktu untuk mencari, namun pemangsa tetap menghabiskan waktu untuk menangani mangsa. Manusia sebagai pihak yang melalukan pemanenan mengambil mangsa persatuan waktu. Dengan melihat fenomena yang ada, hal-hal yang memengaruhi jumlah populasi mangsa dan pemangsa adalah sebagai berikut: 
1. Jumlah populasi mangsa bertambah disebabkan karena adanya laju pertumbuhan alami mangsa dan akan berkurang jumlah populasinya karena adanya pemangsaan yang dilakukan oleh pemangsa serta adanya pemanenan.

2. Pemangsa sepenuhnya bergantung terhadap mangsa karena hasil dari pemangsaan akan berpengaruh dalam meningkatkan produktivitas pemangsa. Jumlah populasi pemangsa akan berkurang diakibatkan karena adanya kematian alami pada pemangsa.

Berdasarkan asumsi diatas maka dapat dibuat skema dibawah ini

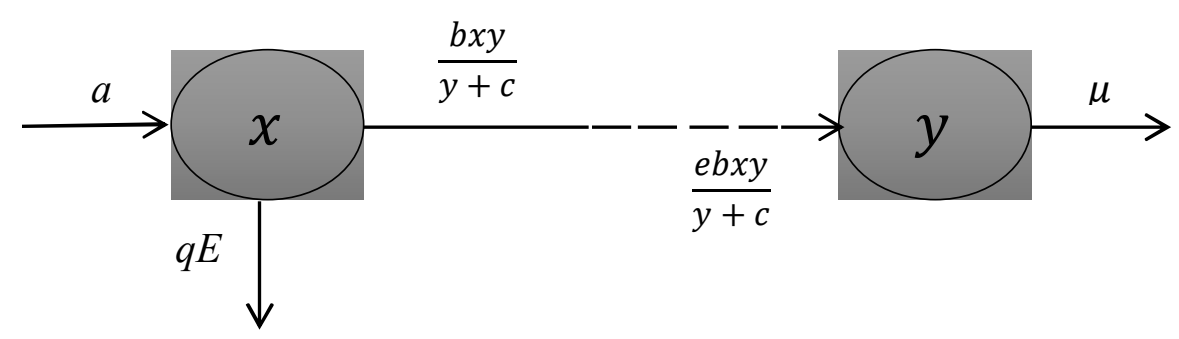

Pengaruh langsung

$---\rightarrow$ Pengaruh tidak langsung

Gambar 1 Skema Model Mangsa Pemangsa dengan Pemanenan pada Mangsa

Sehingga diperoleh persamaan mangsa pemangsa dengan pemanenan pada mangsa sebagai berikut [2]:

$$
\begin{gathered}
\frac{d x}{d t}=a x\left(1-\frac{x}{K}\right)-\frac{b x y}{y+c}-q E x \\
\frac{d y}{d t}=-\mu y+\frac{e b x y}{y+c}
\end{gathered}
$$

dengan:

\begin{tabular}{|c|l|c|}
\hline Notasi & Deskripsi & Interval \\
\hline$x$ & populasi mangsa pada saat $t$ & $x \geq 0$ \\
\hline$y$ & populasi pemangsa pada saat $t$ & $y \geq 0$ \\
\hline$\frac{d x}{d t}$ & $\begin{array}{l}\text { laju perubahan jumlah populasi mangsa pada } \\
\text { saat } t\end{array}$ & $\frac{d x}{d t} \geq 0$ \\
\hline$\frac{d y}{d t}$ & $\begin{array}{l}\text { laju perubahan jumlah populasi pemangsa } \\
\text { pada saat } t\end{array}$ & $\frac{d y}{d t} \geq 0$ \\
\hline$a$ & laju pertumbuhan alami mangsa & $a \in \mathbb{R}^{+}$ \\
\hline$K$ & Carrying capacity mangsa atau daya dukung & $K \geq 0$ \\
\hline
\end{tabular}




\begin{tabular}{|c|l|c|}
\hline & mangsa & $K \in \mathbb{Z}^{+}$ \\
\hline$b$ & Parameter interaksi pemangsaan & $0<b<1$ \\
& & $b \in \mathbb{R}^{+}$ \\
\hline$c$ & Parameter kematian lain mangsa diluar & $0<c<1$ \\
& predasi & $c \in \mathbb{R}^{+}$ \\
\hline$q$ & Parameter daya penangkapan mangsa & $0<q<1$ \\
& & $q \in \mathbb{R}^{+}$ \\
\hline$E$ & Parameter upaya pemanenan mangsa & $E \in 0$ \\
& & $0<\mu<1$ \\
\hline$\mu$ & Parameter kematian alami pemangsa & $\mu \in \mathbb{R}^{+}$ \\
\hline & & $0<e<1$ \\
\hline & Parameter efisiensi perpindahan energi & $0 \in \mathbb{R}^{+}$ \\
\hline & (biomass) & 0 \\
\hline
\end{tabular}

Metode Runge-Kutta Fehlberg ini merupakan metode Runge-Kutta orde 4 yang memiliki ketelitian sampai orde 5. Ketelitian ini disebabkan karena pada metode RKF 45 memiliki 6 buah konstanta perhitungan antara yang berperan untuk memperbaharui solusi sampai orde 5 .

Untuk mempertimbangkan sistem persamaan iterasi ke-i dengan masalah nilai awal

$$
y_{i}^{\prime}=f\left(t, y_{i}, \cdots, y_{n}\right) ; y_{i}\left(t_{0}\right)=y_{0}, i=0,1,2, \ldots, n,[3]
$$

dengan setiap persamaan merupakan persamaan diferensial orde pertama.

Sebelum mendapatkan formula dari metode RKF 45, haruslah mencari konstanta terlebih dahulu. Maka, aproksimasi untuk solusi masalah nilai awal Runge-Kutta orde-4 adalah [3]:

$$
y_{i+1}=y_{i}+\frac{25}{216} k_{1}+\frac{1408}{2565} k_{3}+\frac{2197}{4101} k_{4}-\frac{1}{5} k_{5} ; i=1,2, \ldots, n
$$

dengan galat $\approx O\left(h^{5}\right)$

Untuk solusi yang lebih baik harus menggunakan metode RK orde-5 [3]

$i=0,1,2, \ldots, n$

$$
y_{i+1}=y_{i}+\frac{16}{135} k_{1}+\frac{6656}{12.825} k_{3}+\frac{28.561}{56.430} k_{4}-\frac{9}{50} k_{5}+\frac{2}{55} k_{6} ;
$$

dengan galat $\approx O\left(h^{6}\right)$ dan global $\approx O\left(h^{5}\right)$

Formula untuk estimasi eror dari metode RKF adalah

$$
E=\frac{1}{360} k_{1}+\frac{128}{4275} k_{3}+\frac{2197}{7524} k_{4}+\frac{1}{50} k_{5}+\frac{2}{55} k_{6}
$$


Algoritma Metode Runge-Kutta-Fehlberg dalam menyelesaikan Sistem Persamaan Diferensial Model Mangsa Pemangsa dengan Pemanenan pada Mangsa

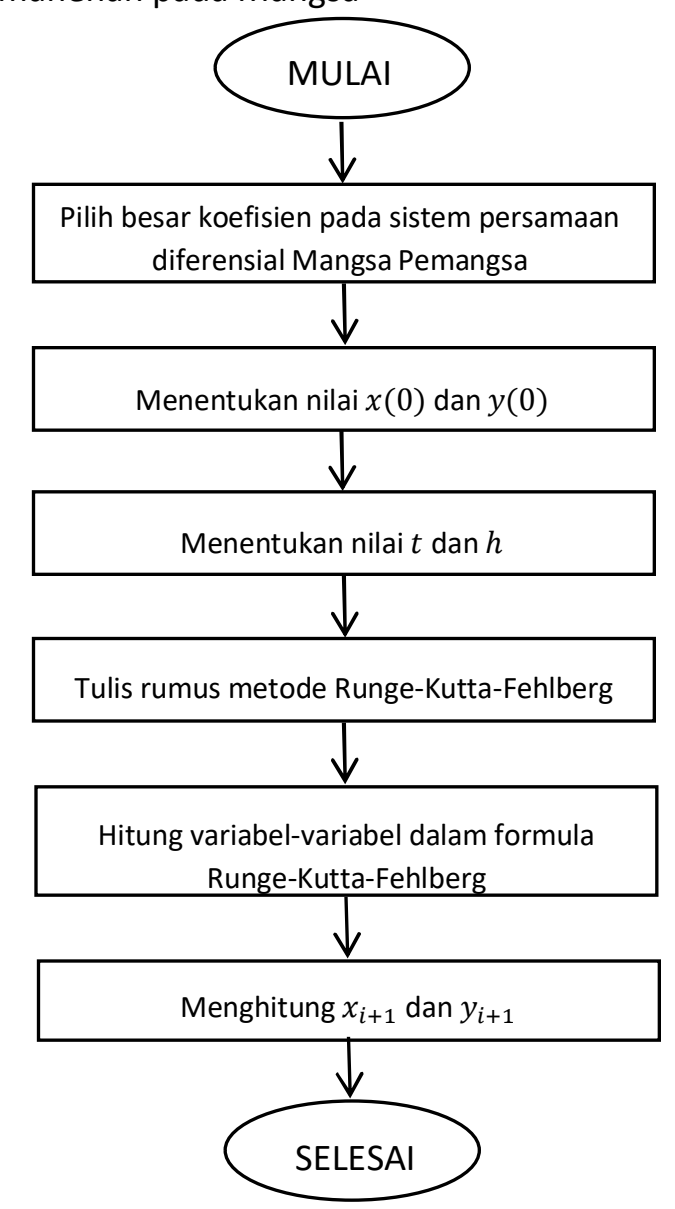

Gambar 2 Flowchart Algoritma Metode Runge-Kutta-Fehlberg

\section{Hasil dan Diskusi \\ Langkah 1}

Pilih besaran koefisien laju kelahiran spesies mangsa yaitu $a=0,2$, carrying capacity mangsa yaitu $K=$ 1000 , parameter interasi pemangsaan yaitu $b=0,1$, parameter kematian lain pada mangsa diluar predasi yaitu $c=0,01$, parameter daya penangkapan mangsa yaitu $q=0,005$, parameter upaya pemanenan mangsa yaitu $E=10$, parameter kematian alami mangsa yaitu $\mu=0,02$, dan parameter efisiensi perpindahan energi yaitu $e=0,1$.

\section{Langkah 2}

Pilih untuk kondisi awal jumlah spesies mangsa $x(0)$ adalah 30 sedangkan jumlah spesies pemangsa $y(0)$ adalah 15.

\section{Langkah 3}

Perkembangan spesies mangsa dan spesies pemangsa akan ditinjau dalam waktu 100 hari $(t=100)$ dengan pemantauan akan dilakukan satu kali dalam sehari $(h=1)$. Berdasarkan langkah pertama maka sistem persamaan diferensial Lotka-Volterra dapat ditulis sebagai berikut: 


\section{Langkah 4}

$$
\begin{gathered}
\frac{d x}{d t}=0,2 x\left(1-\frac{x}{1000}\right)-\frac{0,1 x y}{y+0,01}-(0,005)(10) x \\
\frac{d y}{d t}=-0,02 y+\frac{(0,1)(0,1) x y}{y+0,01}
\end{gathered}
$$

$$
\begin{gathered}
x_{i+1}=x_{i}+\frac{25}{216} k_{1}+\frac{1408}{2565} k_{3}+\frac{2197}{4101} k_{4}-\frac{1}{5} k_{5} \\
y_{i+1}=y_{i}+\frac{25}{216} m_{1}+\frac{1408}{2565} m_{3}+\frac{2197}{4101} m_{4}-\frac{1}{5} m_{5}
\end{gathered}
$$

$i=0,1,2, \ldots, n$

\section{Langkah 5}

Menghitung konstanta antara untuk mengerjakan langkah 4. Misalkan

$f\left(t_{i}, x_{i}, y_{i}\right)=\frac{d x}{d t}=0,2 x\left(1-\frac{x}{1000}\right)-\frac{0,1 x y}{y+0,01}-(0,005)(10) x$,

$g\left(t_{i}, x_{i}, y_{i}\right)=\frac{d y}{d t}=-0,02 y+\frac{(0,1)(0,1) x y}{y+0,01}$, dan $h=1$ maka diperoleh

$k_{1}=1,321999, m_{1}=-0,0002, k_{2}=1,334558 m_{2}=0,003104, k_{3}=1,353448, m_{3}=0,008094$,

$k_{4}=1,401552, \quad m_{4}=0,020591, \quad k_{5}=1,454392, \quad m_{5}=0,034317, \quad k_{6}=1,47785, \quad$ dan $m_{6}=$ 0,040837

\section{Langkah 6}

Menghitung perkembangan jumlah spesies mangsa dan spesies pemangsa dalam iterasi pertama $i=0$, yaitu setelah sehari $t=1$, maka perubahan yang terjadi adalah sebagai berikut

$$
\begin{aligned}
x_{1} & =x_{0}+\frac{25}{216} k_{1}+\frac{1408}{2565} k_{3}+\frac{2197}{4101} k_{4}-\frac{1}{5} k_{5} \\
& =30+\frac{25}{216}(1,321999)+\frac{1408}{2565}(1,353448)+\frac{2197}{4101}(1,401598)-\frac{1}{5}(1,454392) \\
& =31,35592 \\
y_{1} & =y_{0}+\frac{25}{216} m_{1}+\frac{1408}{2565} m_{3}+\frac{2197}{4101} m_{4}-\frac{1}{5} m_{5} \\
& =15+\frac{25}{216}(-0,0002)+\frac{1408}{2565}(0,008094)+\frac{2197}{4101}(0,020591)-\frac{1}{5}(0,34317) \\
& =15,00859
\end{aligned}
$$

Dari perhitungan langkah 6 di atas dapat dilihat pada sehari setelah ada interaksi antara spesies mangsa dengan spesies pemangsa, jumlah spesies mangsa dan spesies pemangsa meningkat yaitu 31,35592 untuk jumlah spesies mangsa dan 15,00859 untuk jumlah spesies pemangsa. Ini artinya setelah pemantauan selama satu hari jumlah spesies mangsa yang awalnya 30 ekor menjadi 31 ekor, sedangkan jumlah spesies pemangsa tetap 15 ekor.

Untuk iterasi berikutnya dikerjakan dengan menggunakan software Matlab, hasil perhitungan dan galatnya disajikan pada Lampiran 4 dan Lampiran 5. Iterasi diulang hingga $t=100$. Diperoleh $x_{100}=$ $x(100)=237,89$ dan $y_{100}=y(100)=81,102$. Dengan kata lain, dalam waktu 100 hari, jumlah spesies mangsa dan spesies pemangsa dalam suatu populasi secara berturut-turut 237 dan 81 ekor.

Pada model ini pemanenan merupakan pengontrol populasi mangsa dan populasi mangsa tentu berdampak pada populasi pemangsa, maka akan divariasikan nilai parameter pemanenan yaitu pada nilai daya pemangkapan mangsa $(q)$ yang disajikan pada tabel 1. 
Tabel 1 Solusi Model Mangsa-Pemangsa dengan Pemanenan pada Mangsa Menggunakan Metode Runge-Kutta-Fehlberg

\begin{tabular}{|c|c|c|c|c|c|}
\hline \multirow{2}{*}{ Simulasi } & \multirow{2}{*}{ Nilai parameter $q$} & \multicolumn{2}{|c|}{ Solusi $(t=100)$} & \multicolumn{2}{|c|}{ Rata-rata galat } \\
\hline & & Mangsa & Pemangsa & Mangsa & Pemangsa \\
\hline 1 & 0,005 & 237,89 & 81,102 & 0,020401 & 0,016717 \\
\hline 2 & 0,004 & 293,22 & 102,37 & 0,022384 & 0,018992 \\
\hline 3 & 0,003 & 346,45 & 124,06 & 0,023936 & 0,02086 \\
\hline 4 & 0,002 & 398,21 & 145,86 & 0,025206 & 0,022424 \\
\hline 5 & 0,001 & 449,11 & 167,64 & 0,026281 & 0,023761 \\
\hline 6 & 0,0009 & 454,17 & 169,82 & 0,02638 & 0,023884 \\
\hline 7 & 0,0008 & 459,22 & 171,99 & 0,026478 & 0,024006 \\
\hline 8 & 0,0007 & 464,27 & 174,17 & 0,026574 & 0,024126 \\
\hline 9 & 0,0006 & 469,32 & 176,34 & 0,026669 & 0,024244 \\
\hline 10 & 0,0005 & 474,36 & 178,51 & 0,026763 & 0,024361 \\
\hline 11 & 0,0004 & 479,41 & 180,68 & 0,026855 & 0,024477 \\
\hline 12 & 0,0003 & 484,44 & 182,86 & 0,026946 & 0,02459 \\
\hline 13 & 0,0002 & 489,48 & 185,03 & 0,027037 & 0,024703 \\
\hline 14 & 0,0001 & 494,51 & 187,2 & 0,027125 & 0,024814 \\
\hline 15 & 0,00009 & 495,01 & 187,41 & 0,027134 & 0,024825 \\
\hline 16 & 0,00008 & 495,52 & 187,63 & 0,027143 & 0,024836 \\
\hline 17 & 0,00007 & 496,02 & 187,85 & 0,027152 & 0,024847 \\
\hline 18 & 0,00006 & 496,52 & 188,06 & 0,027161 & 0,024858 \\
\hline 19 & 0,00005 & 497,03 & 188,28 & 0,027169 & 0,024869 \\
\hline 20 & 0,00004 & 497,53 & 188,5 & 0,027178 & 0,02488 \\
\hline 21 & 0,00003 & 498,03 & 188,72 & 0,027187 & 0,024891 \\
\hline 22 & 0,00002 & 498,54 & 188,93 & 0,027196 & 0,024902 \\
\hline 23 & 0,00001 & 499,04 & 189,15 & 0,027204 & 0,024913 \\
\hline 24 & 0,000001 & 499,49 & 189,34 & 0,027212 & 0,044923 \\
\hline 25 & 0,0000001 & 499,54 & 189,36 & 0,027213 & 0,024924 \\
\hline 26 & 0,00000001 & 499,54 & 189,37 & 0,027213 & 0,024924 \\
\hline 27 & 0,000000001 & 499,54 & 189,37 & 0,027213 & 0,024924 \\
\hline 28 & 0,0000000001 & 499,54 & 189,37 & 0,027213 & 0,024924 \\
\hline 29 & 0,00000000001 & 499,54 & 189,37 & 0,027213 & 0,024924 \\
\hline 30 & 0,000000000001 & 499,54 & 189,37 & 0,027213 & 0,024924 \\
\hline 31 & 0,006 & 180,7 & 60,945 & 0,017751 & 0,013911 \\
\hline 32 & 0,007 & 124,41 & 43,003 & 0,014107 & 0,010472 \\
\hline 33 & 0,008 & 75,197 & 28,531 & 0,0091436 & 0,006407 \\
\hline 34 & 0,009 & 39,358 & 18,216 & 0,0027111 & 0,0019404 \\
\hline 35 & 0,01 & 18,075 & 11,694 & 0,00507096 & 0,0025273 \\
\hline
\end{tabular}




\begin{tabular}{|r|c|c|c|c|c|}
36 & 0,011 & 7,4766 & 7,9124 & 0,013992 & 0,0064336 \\
\hline 37 & 0,012 & 2,8255 & 5,8106 & 0,023907 & 0,0095434 \\
\hline 38 & 0,013 & 0,949 & 4,645 & 0,035141 & 0,011806 \\
\hline 39 & 0,014 & 0,23682 & 3,9812 & 0,049645 & 0,013367 \\
\hline 40 & 0,015 & $-0,017043$ & 3,5861 & 0,14994 & 0,014425 \\
\hline 41 & 0,016 & $-0,098352$ & 3,338 & 0,19345 & 0,015149 \\
\hline 42 & 0,017 & $-0,11746$ & 3,1737 & 0,15425 & 0,015661 \\
\hline 43 & 0,018 & $-0,11559$ & 3,059 & 0,15692 & 0,016034 \\
\hline 44 & 0,019 & $-0,10764$ & 2,9754 & 0,14982 & 0,015315 \\
\hline 45 & 0,02 & $-0,098726$ & 2,9121 & 0,1491 & 0,016534 \\
\hline 46 & 0,03 & $-0,050002$ & 2,6632 & 0,19084 & 0,017439 \\
\hline 47 & 0,05 & $-0,025$ & 2,5577 & 0,16324 & 0,017849 \\
\hline 48 & 0,1 & $-0,011111$ & 2,5036 & 0,20461 & 0,018066 \\
\hline 49 & 0,2 & $-0,0052632$ & 2,4818 & 0,60366 & 0,018154 \\
\hline 50 & 0,3 & $-0,0034483$ & 2,4785 & 1,0844 & 0,018169 \\
\hline
\end{tabular}

Dapat dilihat bahwa selama pemantauan untuk simulasi ke-1 sampai simulasi ke-4 baik jumlah populasi mangsa maupun jumlah populasi pemangsa mempertahankan jumlah populasi sebanyak 230-400 ekor pada waktu pemantauan hari ke-70 sampai hari ke-100. Pada simulasi ke-5 sampai simulasi ke-30 populasi mangsa dan populasi pemangsa mempertahankan jumlah populasi sebanyak 450-500 ekor pada waktu pemantauan hari ke-60 sampai hari ke-100. Pada simulasi ke-31 sampai simulasi ke-34 populasi mangsa dan juga populasi pemangsa mengalami kenaikan, hanya saja jumlah populasi bertambah secara lebih lambat daripada kenaikan jumlah populasi pada simulasi ke-1 sampai simulasi ke-30, hal ini disebabkan karena parameter daya penangkapan mangsa simulasi ke-31 sampai simulasi ke-34 lebih besar daripada parameter daya penangkapan mangsa pada simulasi ke-1 sampai simulasi ke30. Pada simulasi ke-35 sampai simulasi ke-37 baik jumlah populasi mangsa maupun jumlah populasi pemangsa tidak mengalami kepunahan selama pemantauan, namun jumlah kedua populasi mengalami monoton turun. Sedangkan pada simulasi ke-38 sampai simulasi ke-50 populasi mangsa mengalami kepunahan. Hal ini disebabkan karena pada simulasi ke-38 sampai simulasi ke-50 besar daya penangkapan mangsanya sebesar 0,013-0,3. Oleh karena itu, semakin besar daya penangkapan mangsa akan menyebabkan jumlah populasi mangsa semakin cepat berkurang.

Dengan begitu kejadian yang diharapkan adalah simulasi ke-1 sampai simulasi ke-34, yaitu dengan besar parameter daya penangkapan mangsa $(q)$ sebesar $0,000000000001 \leq q \leq 0,009$ dengan ratarata galat $0,0019404-0,027213$. Besarnya parameter daya penangkapan mangsa dan rata-rata galat yang dihasilkan berlaku untuk model ini saja. Model ini cocok diaplikasikan untuk suatu populasi yang berada dalam suatu laboratorium.

\section{Kesimpulan}

Dengan bantuan software Matlab diperoleh nilai rata-rata galat untuk setiap simulasi berada pada interval 0,0019404-0,027213 dengan besar daya penangkapan mangsa $(q)$ sebesar 0,000000000001 $\leq$ $q \leq 0,009$. Ini artinya nilai error kurang dari 0,05 yang berarti bahwa metode Runge-Kutta-Fehlberg 
cukup akurat untuk menyelesaikan solusi pada model mangsa-pemangsa dengan pemanenan pada mangsa secara numerik.

\section{Referensi}

[1] "Wikipedia,"[Online]. Available: http://id.m.wikipedia.org/wiki/Ekologi. [Diakses 25 Januari 2019]

[2] A. M. M. A. A. K. Belkhodja, "Optimal Harvesting and Stability for a Prey-Predaktor Model,"Elsevier, pp. 321-336, 2018.

[3] S. P. M. P. B. Susmita Paul, "Numerical solution of Lotka Volterra prey predator model by using Runge-Kutta-Fehlberg Method and Laplace Adomian Decomposition Method," Elsevier, vol. 55, pp.613-617, 2016. 